\title{
Capability of Anaerobic Bioreactors for a Poultry Slaughterhouse Wastewater Treatment
}

\author{
Nazaire Nsanzimana, Seteno Karabo O. Ntwampe, Moses Basitere and Mncedisi T. Dewa
}

\begin{abstract}
Poultry slaughterhouses use as a high quantity of clean water as generate a high volume of wastewater, and anaerobic digestion process known to be an effective way to treat such wastewater at low operation cost. The prominent anaerobic digesters, namely Static Granular Bed Reactor (SGBR) and down flow Expanded Granular Sludge Bed reactor (EGSB) have been appreciated to treat the poultry slaughterhouse wastewater. Previous studies have assessed the performance capacity of both SGBR and EGSB based on their criteria for chemical Oxygen Demand removal efficiency. By contrast, the quality of these reactors depends on multiple characteristics COD removal (\%), FOG removal (\%), BOD removal $(\%)$, OLR (mg/L.hr). Hence a case study approach was used to test their effluent potential, by hypothesis testing multivariate capabilities for both EGSB and SGBR at PSW pilot plant. The visual basic program of excel as statistical software.
\end{abstract}

Keywords-Expanded Granular Sludge Bed, Multivariate process capability indices, Poultry slaughterhouse wastewater, Static granular bed reactor.

\section{INTRODUCTION AND BACKGROUND}

Poultry slaughterhouse is associated with water consumption and a high amount of wastewater generated. The major environmental problem associated with slaughterhouse wastewater is a large amount of organic matter [1] Although a number of cross-sectional studies suggest that better effluent quality of wastewater treatment works are an option to the water resources, due to the growth in environmental limitations that has to be effectively monitored [2]. There is evidence that increasing the need for more efficient water treatment and management, plays a crucial role in attending to the freshwater resource's challenges in both urban and industrial area [3] Debate continues about the best strategies for such management.

The biological anaerobic treatment process is one of the industrial wastewater treatments that is substantiated by biodegradability, treatability. Nowadays, there increase in anaerobic bioreactor use for wastewater treatment plants due to their performance, efficiency and cost-effectiveness. EGSB and

Manuscript received October 14, 2019. This work was supported by the Cape Peninsula University of Technology (CPUT) under Grant UCDG RX 39, and, Bioresource Engineering Research Group (BioERG) under RK45.

Cape Peninsula University of Technology, Department of Industrial and Systems Engineering, and Department of Chemical engineering P.O. Box 1906, Bellville 7535, South Africa.

Bioresource Engineering Research Group (BioERG). Department of Biotechnology , Cape Peninsula University of Technology ( CPUT) , P.O. Box 652, Cape Town 8000, South Africa.
SGBR being ones of low-cost biological treatment processes. The aim of this study was to analyze the capability of both EGSB and SGBR for removing COD, BOD, and FOG from a pilot PSW plant. A case-study approach was chosen to allow a deeper insight into EGSB and SGBR organics (COD, BOD, and FOG ) removal performance using data of record in the previous work of Basitere, Williams [4].

\section{PROCESS CAPABILITY EVALUATION}

Generally, the purpose of monitoring the process is to assist the plant performance to satisfy its operating objectives. Although, the operation of the plant depends on size, and correlation of process variables. It is then important to point key variables that can have significant consequences for plant safety, the environment, product quality, and plant profitability. Hence methodology involved steps as shown in Fig.1.

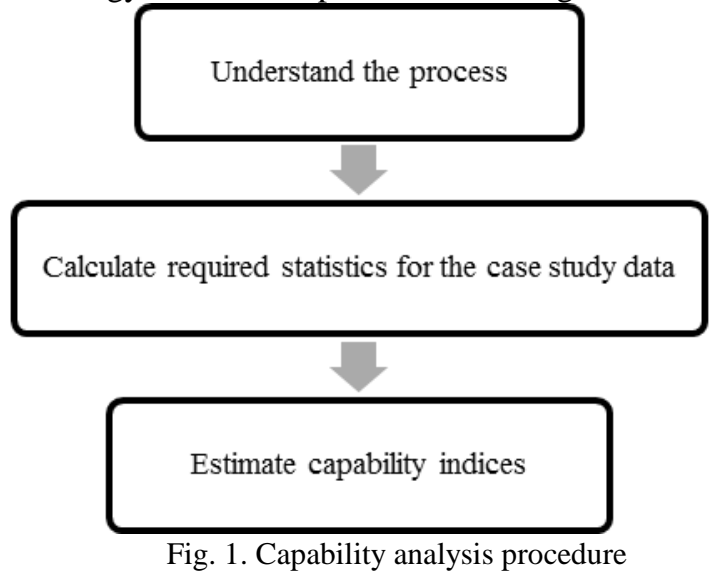

\section{A. Case Study and Data}

The case study related to measuring the capability and performance of effluents of EGSB and SGBR reactors to remove organics (COD, BOD, and FOG). Generally, data must be collected in such a way they are appropriate, differ from their costs, time and other resources at the disposal of the research [5]. Hence primary and secondary data from at PSW pilot plant-like COD removal (\%), FOG (\%), BOD (\%), OLR (mg/L.hr) recorded in the previous work of Basitere, Williams [4] shown in Table I ; Sample of an experimental data of organics removal through SGBR presented in Table II, and Table III exemplifies Organics removal standards. They were used to examine the truth contained in the hypothesis for the state on capabilities of both EGSB and SGBR at the PSW pilot plant. 
TABLE I: SAMPLE OF AN EXPERIMENTAL DATA OF ORGANIC MATTER REMOVAL BY EGSB

\begin{tabular}{lccc}
\hline \hline Day & $\begin{array}{c}\text { COD } \\
\text { removal }(\%)\end{array}$ & $\begin{array}{c}\text { BOD } \\
\text { removal }(\%)\end{array}$ & $\begin{array}{c}\text { FOG } \\
\text { removal }(\%)\end{array}$ \\
\hline 7 & 73,02 & 84,71 & 87,14 \\
14 & 97,03 & 98,59 & 95,54 \\
21 & 97,54 & 98,91 & 94,68 \\
28 & 93,16 & 94,67 & 92,34 \\
35 & 94,36 & 98,29 & 91,16 \\
42 & 97,10 & 99,23 & 93,77 \\
49 & 97,44 & 98,76 & 94,83 \\
56 & 95,33 & 92,80 & 85,46 \\
63 & 97,34 & 98,82 & 96,28 \\
70 & 94,95 & 98,48 & 98,07 \\
77 & 96,39 & 98,83 & 96,64 \\
84 & 97,96 & 97,84 & 96,99 \\
91 & 99,61 & 99,88 & 99,42 \\
98 & 99,06 & 99,51 & 98,17 \\
105 & 97,22 & 98,29 & 84,57 \\
\hline \hline
\end{tabular}

TABLE II: SAMPLE OF AN EXPERIMENTAL DATA OF ORGANIC MATTER REMOVAL BY SGBR

\begin{tabular}{rccc}
\hline \hline Days & \multicolumn{2}{c}{ TCOD removal } \\
$(\%)$ & \multicolumn{2}{c}{$\begin{array}{l}\text { BOD removal } \\
(\%)\end{array}$} & \multicolumn{2}{c}{$\begin{array}{l}\text { FOG removal } \\
(\%)\end{array}$} \\
\hline 28 & 74,1 & 93 & 45,3 \\
29 & 78,0 & 94 & 82,8 \\
27 & 78,6 & 91 & 91,8 \\
28 & 85,5 & 96 & 93,6 \\
26 & 85,4 & 93 & 89,7 \\
\hline \hline
\end{tabular}

TABLE III: ORGANIC MATTER REMOVAL STANDARDS

\begin{tabular}{ccccc}
\hline \hline Parameter & S. D $(\sigma)$ & Min & Max & Median \\
\hline $\begin{array}{c}\text { TCOD } \\
\text { removal (\%) } \\
\text { BOD } \\
\begin{array}{c}\text { average (\%) } \\
\text { FOG }\end{array}\end{array}$ & 3,63 & 49,39 & 98,05 & 95,68 \\
removal (\%) & 3,58 & 84,71 & 99,23 & 98,59 \\
\hline \hline
\end{tabular}

\section{B. EGSB, SGBR, and Organics (COD, BOD, and FOG) Removal Process Overview}

Normally process outputs (Ys) are subjected to the inputs (Xs), and to monitor the process, requires to link outputs to the needs (quality) and expectations of the customer. Quality practitioners associate the Voice of the Process (VOP) with the Process Output Variables (POV). By considering VOP, as an operation of all the inputs. Fig. 2 illustrates the organics removal process through either EGSB or SGBR. COD is used to test concentration of organic matter, while BOD helps to test organic matter in wastewater. FOG components in wastewater, have low solubility that lower biodegradability by microorganisms.

Poultry slaughterhouse wastewater has led to a concern of high organics, hence confronted by the quality standard to fit recycling and reuse. SGBR and EGSB being one of technology extensively used to treat PSW, and by contrast, these reactors need adequate monitoring in the organics removal process. As the aim was to Test and analyze capability performance for organics ( COD, BOD, and FOG) removal through EGSB and SGBR, The capability analysis procedures based on multivariate characteristics of a sample of experimental data in Table I and II from at PSW pilot plant, was evaluated.

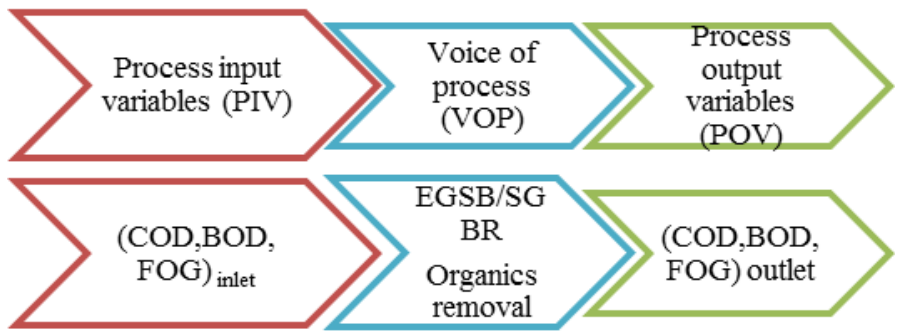

Fig. 2. Process overview.

\section{Final Stage Organics (COD, BOD, and FOG) Removal Process Capability Analysis in EGSB and SGBR}

According to Scagliarini [6] multivariate capability index $\mathrm{MCpm}$, is given by the volume of engineering tolerance region divided by the one of modified process region, as shown in Eq. (1).

$M C_{p m}=\frac{\tau_{p}}{D}$

Where $C p$ stands for the process variability comparative to the modified tolerance region, and $D$ stands for the process deviation from the target. For estimating MCpm index, there is a need of a random sample $n$, number of characteristics $v$ (dimension), $\alpha$ value to define the size of the tolerance region (usually $\alpha=0.0027$ ). The sample data in Table I, II, and III were processed respectively to assess the capability of EGSB and SGBR for organics removal processes of a pilot PSW plant.

\section{Assumptions}

$i$. The organics removal processes through EGSB and SGBR are stable and approximately normally distributed.

ii. The organics removal processes through EGSB and SGBR do not depend on temperature, HRT and OLR.

E. Hypothesis Testing for Organics (COD, BOD, and FOG) Removal Process Capability

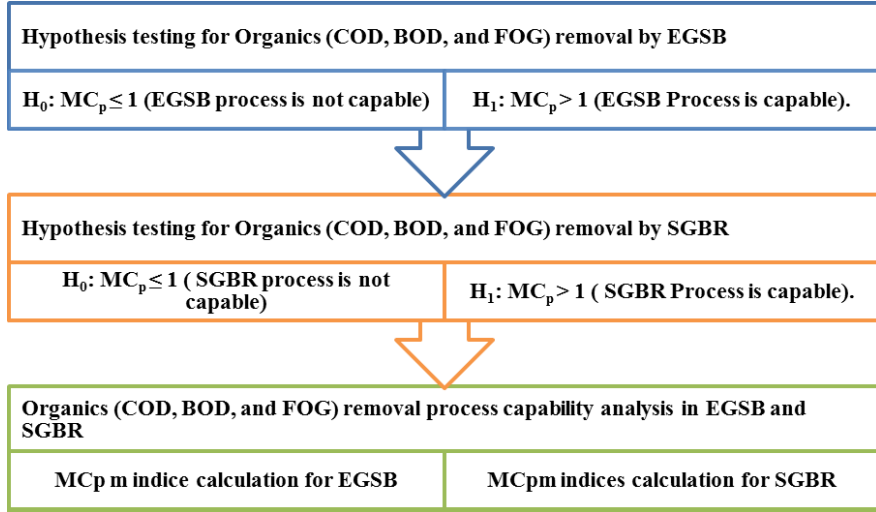

Fig.3: Hypothesis testing for Organics (COD, BOD, and FOG) removal process capability. 
Following the steps shown in Fig. 3, it was determined whether or not Organics (COD, BOD, and FOG) removal processes were capable.it was done based on data from Table I and II from at PSW pilot plant, and using excel spreadsheet with instructions provided by Scagliarini [6], MCpm indices were estimated.

\section{RESULTS AND DISCUSSION}

MCpm indices (MCpm, MCp, and D) were calculated via excel software, and outputs are shown in Table IV. Where index (MCpm) was found to be 0.06 , which means the multivariable of COD, BOD, and FOG removal process capability analysis in EGSB has found to have a bigger variation than allowed by the specification limits. Secondly, MCp (the modified tolerance region) was found to be 0.11 and the volume of the scaled 99.73 percent process region (D) was 1.79 which means that the closeness of process mean to the target was $1 /(1,79)$.

Based on the value of MCp of 0.11 that was smaller than one, COD, BOD, and FOG removal process capability analysis in EGSB revealed that the EGSB process was incapable at 0.0027 level of significance.

MCpm indices (MCpm, MCp, and D) were calculated via excel software, and outputs are shown in Table V, and index (MCpm) was found to be 0.04 , which means the multivariable of COD, BOD, and FOG removal process capability analysis in SGBR has found not to conform with presumed by the specification limits. Secondly, MCp (the modified tolerance region) was found to be 0.22 given the scaled volume of 99.73 percent process region. D was 4.95 which mean that the closeness of process mean to the target was $1 /(4,95)$.

Based on the value of MCp of 0.22 that was smaller than 1 , Organics (COD, BOD, and FOG) removal process capability analysis in SGBR revealed that the SGBR process was incapable at 0.0027 level of significance.

\begin{tabular}{cc} 
TABLE IV: EGSB CAPABILITY INDICES RESULTS \\
\hline \hline MCpm index & value \\
\hline $\mathrm{MC}_{\mathrm{pm}}$ & 0,06 \\
$\mathrm{MC}_{\mathrm{p}}$ & 0,11 \\
$\mathrm{D}$ & 1,79 \\
\hline \hline
\end{tabular}

TABLE V: SGBR CAPABILITY INDICES RESULTS

\begin{tabular}{cc}
\hline \hline $\mathrm{MCpm}$ index & value \\
\hline $\mathrm{MC}_{\mathrm{pm}}$ & 0,04 \\
$\mathrm{MC}_{\mathrm{p}}$ & 0,22 \\
$\mathrm{D}$ & 4,95 \\
\hline \hline
\end{tabular}

\section{CONCLUSION}

This study set out to assess whether organics (COD, BOD, and FOG) removal by both EGSB and SGBR processes were capable at 0.0027 level of significance. This research found both processes incapable; hence a design of EGSB or SGBR coupled with both pre and post-treatment should be an option.
Also, this study can be extended to develop nutrients and solids removal process for EGSB and SGBR.

\section{REFERENCES}

[1] Mittal, G.S., Treatment of wastewater from abattoirs before land application-a review. Bioresource technology, 2006. 97(9): p. 1119-1135. https://doi.org/10.1016/j.biortech.2004.11.021

[2] Naidu, R., et al., Emerging contaminants in the environment: risk-based analysis for better management. Chemosphere, 2016. 154: p. 350-357. https://doi.org/10.1016/j.chemosphere.2016.03.068

[3] Loucks, D.P. and E. Van Beek, Water resource systems planning and management: An introduction to methods, models, and applications. 2017: Springer.

https://doi.org/10.1007/978-3-319-44234-1

[4] Basitere, M., et al., Performance of an expanded granular sludge bed (EGSB) reactor coupled with anoxic and aerobic bioreactors for treating poultry slaughterhouse wastewater. Water Practice and Technology, 2016. 11(1): p. 86-92. https://doi.org/10.2166/wpt.2016.013

[5] Kothari, C.R., Research methodology: Methods and techniques. 2004: New Age International.

[6] Scagliarini, M. and R. Vermiglio, Computing Multivariate Process Capability Indices (Excel). Journal of Modern Applied Statistical Methods, 2008. 7(1): p. 30.

https://doi.org/10.22237/jmasm/1209616140

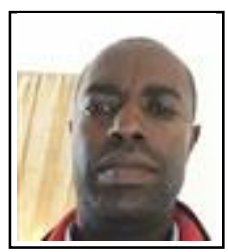

Nazaire Nsanzimana is a laboratory technician in the Departments of Mathematics and Physics at the Cape Peninsula University of Technology. He holds a National Diploma in Mathematical Technology and a BTech in Quality. He is currently pursuing his Master of Engineering in Quality. 